\title{
Ética e racionalidade científica: desafios à Psicologia como ciência e profissão
}

Uma das características básicas da produção de conhecimento e divulgação do científico é o esforço constante de seus protagonistas em sistematizar experiências humanas, nas circunstâncias em que elas ocorrem e conforme o estado da arte das pesquisas a elas relacionadas. Publicar resultados de pesquisas é um compromisso que os cientistas são compelidos a cumprir, de forma a continuar construindo o avanço do conhecimento e a tornar acessível as informações produzidas. A publicação dos resultados de pesquisas procura alcançar três objetivos: a) estimular a reflexão e a crítica; b) divulgar as descobertas científicas; c) alcançar o reconhecimento dentro da comunidade científica e fora dela sobre a relevância dos produtos da ciência. Induzir estratégias de produção e divulgação científicas reflete, portanto, a necessidade da ciência, como modo de conhecer a realidade, em contribuir no processo civilizatório, isto é, reconhecer a importância dos processos educativos e das referências institucionais no processo de formação e desenvolvimento da comunidade humana.

Cada edição da Revista Psicologia: Ciência e Profissão resulta em uma obra coletiva, uma combinação de trabalho técnico, experiências profissionais diferenciadas, processos de avaliação e verificação de vários níveis e atores, envolvimento com produção e divulgação de materiais de boa qualidade, expectativas acerca das repercussões na comunidade. Toda essa combinação de atividades e esforços partem da premissa e do compromisso de a Revista Psicologia: Ciência e Profissão contribuir no processo de divulgação do conhecimento científico em Psicologia e, ao mesmo tempo, ser uma fonte importante de educação profissional. Isso significa ter a pretensão de contribuir na formação científica profissional dos psicólogos (e não somente na formação profissional), a fim de melhor prepará-los para reconhecerem os avanços do conhecimento psicológico e suas aplicações, os parâmetros científicos, limites, benefícios e alcance social da atuação dos psicológicos, a necessidade do rigor teórico e metodológico na produção de conhecimentos e na intervenção psicológica na sociedade.

É cada vez mais evidente a necessidade de a ciência psicológica contribuir mais efetivamente na promoção de soluções para os problemas e desafios socioassistenciais, educacionais, ambientais, éticos e tecnológicos enfrentados pela sociedade brasileira. Seja na pesquisa básica ou aplicada, a produção de conhecimentos em Psicologia deve refletir os seus legítimos interesses e finalidades: ampliar o conhecimento sobre a realidade humana e identificar estratégias de promoção da qualidade de vida das pessoas. A pesquisa científica, portanto, é um empreendimento humano voltado para a humanidade, por mais tautológico que isso possa parecer. Esse é o seu pressuposto ético.

Por outro lado, empreender cientificamente em Psicologia, com base nesse pressuposto e considerando toda a sua expressividade, requer processos de formação profissional que instale e desenvolva mecanismos de compreensão e de operacionalização da racionalidade científica, isto é, a produção e a avaliação de conhecimentos, baseados em critérios válidos e relevantes à ciência e à sociedade, tal como discutidos no campo da epistemologia científica na tradição kantiana - o fenômeno que se conhece é impregnado de teoria -, na lógica popperiana - a ciência como um projeto humano e o papel institucional da ciência na sociedade - e, na perspectiva khuniana - o conhecimento científico é uma das formas de saber humano que tem origem na curiosidade e na necessidade de mudar a explicação sobre a realidade que se vive (Brush, 2000; Cupani, 2005; Kant, 1987; Popper, 1993). 
O conhecimento que se pretende conhecer, em ciência, revela o espírito humano de se orientar não somente pelo conhecido, em termos de teorias, métodos e acúmulo da experiência humana, mas também para um certo desconhecido, resultado da curiosidade, estranhamento e inventividade humanas. A racionalidade científica, nesse sentido, é uma condição necessária para produzir o conhecimento e aplicá-lo. A Ciência, diferente das demais formas de conhecimento criadas pelos seres humanos, é um projeto sistematicamente utilizado para compreender o próprio conhecimento. São premissas de sua existência: lidar com a incerteza, a dúvida e a insegurança que fazem parte dos processos de conhecer. Portanto, a ciência, embora se apresente, eventualmente, sobre a áurea da verdade, é falível.

Aprender a sistematizar observações e construir perspectivas teóricas, métodos ou estratégias de intervenção na sociedade refletem o esforço humano de tentar compreender fenômenos e processos inerentes à condição humana e à sua existência, equivalente à busca da verdade, no sentido filosófico: algo que nunca se atinge totalmente, mas para o qual se orienta permanentemente o conhecimento humano (Cruz, 2004).

É tarefa da racionalidade científica, portanto, contribuir para o desenvolvimento de condutas profissionais que auxiliam na construção de sociedades orientadas por preceitos éticos cada vez mais avançados, uma vez que não existem sociedades constituídas só por virtuosos ou por células sociais eficazes (Sá, 2000). Concorre, portanto, para orientar e demarcar os limites da ciência e da atuação profissional, a racionalidade científica e seus derivados: a capacidade técnica e as competências socioprofissionais desenvolvidas nos processos de formação científica ao longo da instrução educativa. Nessa direção, a ética é herdeira da discussão dos processos de conhecer, seja no âmbito da racionalidade científica, da moral ou dos fundamentos da ação humana (Maciel, Frizzo, \& Castro, 2010). Por isso, é essencial, na formação científica profissional, a busca pelo conhecimento das condições em que são gerados os conhecimentos e suas aplicações, assim como os meios necessários para construí-los e implementá-los.

A conduta ética em ciência está diretamente relacionado à ética dos processos de conhecer e da aplicação de conhecimentos - razão de ser do empreendimento científico na sociedade. A ciência não é, enquanto prática institucionalizada, isolada do resto da sociedade, muito pelo contrário. Os rumos da pesquisa científica não são ditados pelo próprio saber científico, e sim por pessoas com interesses diversos e, frequentemente, conflitantes. Compreender o processo de conhecer o que se conhece, ou o que não se conhece, é compreender o discurso científico, que é uma forma de realização do que é propriamente humano: a vontade de aprender.

O desafio da experiência ética, que se realiza no campo discursivo (ao produzir ciência e publicar seus resultados), é provocado nas relações de convivência, que exigem atenção ao compromisso e cuidado com os valores fundamentais. Tudo isso implica em considerar que os propósitos da racionalidade científica são afetos à historicidade e às determinantes biopsicossociais, à necessidade da manutenção do ideal democrático, o respeito às diferenças e à liberdade individual e os desafios postos pela construção de parâmetros que levem em conta a institucionalização do conhecimento científico na sociedade.

A Revista Psicologia: Ciência e Profissão faz parte do processo de institucionalização do conhecimento psicológico na comunidade científica. É, também, herdeira da racionalidade científica ao comunicar a diversidade da produção científica em Psicologia e a qualidade dos processos de intervenção psicológica em diferentes contextos. Por isso, os processos de conhecer, nela expressos, devem também expressar condutas éticas promotoras do saber científico na comunidade e da educação profissional.

\section{Roberto Moraes Cruz}

Universidade Federal de Santa Catarina

Editor 
Brush, S. (2000). Thomas Kuhn as a historian of science. Science \& Education, 9, p. 39-58.

Cruz, R. M. (2004). O processo de conhecer em avaliação psicológica. In R. M. Cruz, J. C. Alchieri, \& J. J. Sardá Junior (Orgs.), Avaliação e medidas psicológicas: produção do conhecimento e da intervenção profissional (pp. 15-24). São Paulo, SP: Casa do Psicólogo.

Cupani, A. O. (2005). Compreendendo melhor a racionalidade da ciência. In M. Pietrocola, \& O. Freire (Org.), Filosofia, ciência e história. São Paulo, SP: Discurso.
Kant, I. (1987). Crítica da razão pura (3a ed.). São Paulo, SP: Nova Cultural.

Maciel, S. K., Frizzo, N. P., \& Castro, M. C. D. (2010). Ensino de ética profissional na formação dos psicólogos do Brasil. Revista Electrónica de Investigación y Docencia, 3(Enero), 37-54.

Popper, K. R. (1993). A lógica da pesquisa científica. São Paulo, SP: Cultrix.

Sá, A. L. (2000). Ética profissional (2a ed.). São Paulo, SP: Atlas. 